\title{
Eeditoxial
}

\section{A Profile of Current pharmacy Education in The Sudan Mohamed Alzain Mohamed Haga ${ }^{1}$ and Eltayeb Mohamed Eltayeb Gamereldeen ${ }^{2} *$}

The first pharmacy college affiliated to University of Khartoum was established in (1963) with intake of only twenty students per year. This policy of admission continued with no substantial annual increase in the number of students enrolled in the college of pharmacy. However, after the revolution of higher education in the (1990) (s), the number of governmental and national pharmacy colleges has multiplied enormously.

Today there are about thirteen pharmacy colleges with possibly more in the pipeline. It is true that expansion in higher education is a requirement for national development, albeit, a clear strategy should be envisaged whereby quality of the university graduate matters mare than number. Pharmacy graduates of the last ten years or so labored in an environment of severe shortages of qualified teaching staff and facilities. These graduates are understandably of low standards and consequently their contribution in health care will be poor.

$\mathrm{R}$

ecently, Sudan Medical Council (SMC) organized a workshop on the The accredition is intended to protect public The accreditation is intended to protect public safety by ensuring that health care is delivered by pharmacists in a professional, safe, and competent manner. Logically, to execute their duty adequately, pharmacists should first receive proper university education.

The authors, of this article are glad that SMC took the initiative to organize the workshop with the objectives of raising the awareness about the significance and purpose of accreditation and about accreditation standards of pharmacy schools. Clearly SMC is aware of the problems now facing pharmacy education and graduate pharmacists.

The authors had access to the program of the workshop on the (Accreditation of Pharmacy Schools). Although the six speakers are pharmacy professors of high expertise and lifelong experience, yet what they presented would unlikely be implemented in the Colleges under their administration.

1. Pharmacy program, Khartoum College of medical sciences. Khartoum, Sudan

2. Faculty of pharmacy, Omdurman Islamic University

* Correspondence
A real change in the current pharmacy education is expected to come from the governmental colleges and not from the national counterparts which understandably cannot afford cost-ineffective measures. The government has an obligation to pay for providing sound education and to maintain strict policy about accreditation standards of any pharmacy college.

Prompted by the recent initiative ${ }^{1}$ taken by SMC for the accreditation of pharmacy schools, the authors believe that the first step to achieve that goal is to outline a model fiveyear pharmacy curriculum by a committee of experts. This exemplary curriculum should be structured along the guidelines proposed by the SMC, and more important this curriculum must be adopted by all schools of pharmacy. A mechanism whereby faithful adoption of the model curriculum is observed by the colleges should be worked out. Tailoring and implementation of a model pharmacy curriculum entails that an adequate number of qualified teaching staff should be available. But now in the light of the scarcity of qualified PhD holders, colleges of pharmacy depend to large extent on an inexperienced teaching staff. The situation is complicated further by the participation of a substantial number of non-pharmacists in the teaching process. 
Having said that, the authors would like to make it clear that non-pharmacist Ph. D. holders can participate fruitfully in the first two years of pharmacy programs where basic disciplines such as chemistry, biology, mathematics, physics , ... etc are dealt with . The three remaining years of pharmacy courses are entirely applied i.e. pharmaceutical. In these three years, the main disciplines of pharmacy i.e. pharmaceutics, pharmacology, pharmaceutical chemistry, pharmacognosy and clinical pharmacy, are taught in an integrated manner. The outcome is a pharmacist whose qualification is a blend of a homogenous combination of disciplines peculiar to pharmacy. It is clear that anonpharmacist has no leading role to play in the last three years of pharmacy program. However, under the pretext of shortage of teaching staff this is now taking place. Obviously under these sad circumstances pharmacy students will be the victims and pharmacy profession will be sacrificed too. To rectify the situation, existing colleges of pharmacy should be persuaded to recruit qualified members of staff. In addition, approval for establishing new colleges of pharmacy is meaningless and detrimental.

In addition to the first two years of pharmacy program, competent pure scientists may actively participate in the post- graduate studies since basic research and applied research go hand in hand. All in all the authors of this article advocate the cooperation with competent pure scientists during the first two years of pharmacy program and in the post-graduate studies within the pharmaceutical setting. In two recent reports ${ }^{2,3}$ the structures of the existing pharmacy curricula were discussed and a number of proposals had been advanced. In these proposals an integrated teaching approach of pharmaceutical subjects was stressed. Furthermore, collaboration in research activities of pharmacy colleges and post-graduate studies was welcome.

An exemplary pharmacy curriculum should include not only the traditional disciplines but in addition should include pharmacy ethics, medical psychology, medical sociology biostatistics, hygiene and public health. The curriculum should also provide the knowledge, concepts skills and attitudes necessary for good communication with other colleagues. The leaning process in the existing pharmacy curricula is to a large extent based on dishing out of information to be retrieved in an examination. On the contrary, the model pharmacy curriculum should promote critical thinking and active student participation in the learning process. A research project as partial fulfillment of graduation will teach students research methodology and promote communication and presentation skills.

In conclusion the authors are glad that the SMC has taken the initiative for the accreditation of colleges of pharmacy in line with the requirements of World Federation for Medical Education (WFME). It is the hope of many of our colleagues in the colleges of pharmacy that Sudan Medical council will go ahead to accomplish the mission and remedy the situation in collaboration with the Ministry of Higher Education and other stakeholders concerned. Further, the authors appreciate the endeavor of the SMC for organizing the workshop and pray that this will lead to the resurrection of pharmacy education in the Sudan. It is also important to remember that the design of a model curriculum is relatively easy, but the question is: who is going to teach the curriculum? And to what depth and breadth it will be covered?

\section{References :}

1. Sudan Medical Council, Accreditation Department, Workshop on Accreditation of pharmacy Schools, 2010, Khartoum, Sudan.

2. Haga M, EL NIMA IE . The Challenges of Pharmacy Education in the Sudan. Gezira Journal of Health Sciences 2009; 5 (1): 1-4 .

3. Haga M, Abdelraheem E . A new Approach to Teaching Physical Pharmacy, Omdurman Journal of Pharmaceutical Sciences 2008; 4: 558 - 561 . 


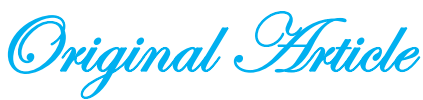

Audit of ERCP at Ibn Sina Hospital from 2009-2010

Nasreeldeen Adam Ali ${ }^{1}$, Abdelmoiem Eltayeb ${ }^{2}$, Tarig Mohamed Husien ${ }^{2}$, Mohamed ${ }^{2}$ O M Sulaiman, Bahauldeen Gasm El Seed ${ }^{2}$, MAM Ibnouf ${ }^{3}$

\section{Abstract \\ Background:}

Surgeons are expected to deal with expect some failure of ERCP in extraction of missed CBD stones. Re-do surgery is difficult; however surgeons have to stand for it.

\section{Objectives:}

To audit the outcome of ERCP in extraction of CBD stone for patients referred to Ibn Sina Teaching Hospital.

\section{Material and methods:-}

Study design:-This is prospective, hospital based study; carried in the period from January 2009 to June 2010 in Ibn Sina Teaching Hospital .A total of 119 patients referred for ERCP extraction of CBD stones were studied.

\section{Results:}

Male to female ratio was 1:5. The mean age $( \pm \mathrm{SD})$ is $55.4( \pm 17.57)$. Post cholecystectomy missed stones were $7(6 \%)$, post CDB exploration retained stones were $4(3.4 \%)$ and re-do ERCP was done in $9(7.6 \%)$ patients.

Failure of stone extraction occurred in $10(25 \%)$ cases due to failure of cannulation while another $10(25 \%)$ cases had multiple impacted stones and nine $(22.2 \%)$ had too big stone to be extracted. In addition, five $(12.5 \%)$ cases had CBD stricture, and the procedure was not completed because of bleeding in two cases and impaction of the dormia basket in two (5\%) cases. The success of redo ERCP is seven out of nine cases. Complication occurred in seven $(5.88 \%)$ patients. These were bleeding in two $(1.68 \%)$, cholangitis in one $(0.84 \%) \mathrm{CBD}$ and retro-peritoneal duodenal perforations in two $(1.68 \%)$ and retained dormia basket in two $(1.68 \%)$ cases. The mortality rate was one $(0.8 \%)$ patient.

\section{Conclusion:}

ERCP, at Ibn Sina Hospital, has success rate in stone extraction in 79(66.4\%) and complication rate in seven $(5.88 \%)$ patients. About one third of cases attending ERCP for stone extraction were referred back for open exploration of CBD.

Keywords: cholecystectomy, CDB exploration, impacted stones.

$\mathrm{E}$ ndoscopic retrograde cholangiopancreatography (ERCP), MRCP and EUS have comparable sensitivity and specificity in the diagnosis of choledocholithiasis ${ }^{\mathbf{1 , 2}}$. With these newer diagnostic imaging technologies emerging, ERCP is evolving into a predominantly therapeutic procedure.

\footnotetext{
1. Registrar of surgery. IbnSina Hospital.

2. Consultant surgeon. IbnSina Hospital.

3. Prof of surgery. Omdurman Islamic University.

4. Correspondence: maibnouf@gmail.com
}

ERCP is a complex endoscopic procedure, has long learning curve to develop proficiency, however, it is not without complication. Complications of ERCP may occur as medication reactions, oxygen desaturation, cardiopulmonary accidents, haemorrhage, perforation and sepsis. Moreover, transient a symptomatic pancreatitis is frequent.

At least 180 procedures are required for a trainee to acquire a level of competence in diagnostic and therapeutic ERCP, which allows cannulation of the bile duct in 70 to 80 percent of cases ${ }^{3}$. Nevertheless, 90 to $95 \%$ 
success can be achieved by experts ${ }^{4}$. Individual endoscopists who perform more than 40 endoscopic sphincterotomies per year or at least one per week have a lower complication rate than those who perform fewer procedures ${ }^{5}$.

Retained or recurrent stones following cholecystectomy are best treated endoscopically.

Objectives:-

To find out success and complication rates of ERCP in extraction of CBD stones in patients seen in IbnSina Teaching Hospital.

Material and methods:-

Study design:This is prospective case series study, hospital based study, carried in the period from January 2009 to June 2010 in IbnSina Teaching Hospital.

Setup:-GIT endoscopy unit in IbnSina Teaching Hospital. Two surgeons and two physicians with experience ranging from 210 years in ERCP.

Inclusion criteria: All patients diagnosed as CBD stones referred for ERCP with or without jaundice in the period between January 2009 to June 2010 are included in the study $(\mathrm{n}=119)$.

Exclusion criteria: Cases of CBD stones booked for surgery from the start, jaundiced patient with carcinoma head of pancreas, cholangiocarcinoma, periampullary carcinoma and jaundiced patient with $\mathrm{CBD}$ injury were excluded.

Patients were reviewed for age, sex, success and failure of $\mathrm{CBD}$ stones extraction, causes of failure, and complications.

Statistical analysis: The collected data analyzed using computer program Statistical Package for Social Science (SPSS). Mean, standard deviation and one $t$ test sample were used where appropriate. Statistical significance was taken at $\mathrm{P}<0.05$.

\section{Results}

A total of 119 patients with CBD stones treated by ERCP in Ibn Sina Teaching Hospital in the period between January2009 to June2010 were studied. They were 18 males and 91 females.

The mean age is $55.4( \pm 17.57)$ range of 19 to 90 years. Post cholecystectomy missed stones were 7(6\%) (Table 1), post CDB exploration retained stones were $4(3.4 \%)$ and ERCP was re-done in $9(7.6 \%)$ patients.

Table 1: frequency of stone extraction among operated and those who were not operated

\begin{tabular}{c|ccc} 
History of & \multicolumn{4}{|l}{ Stone extraction } \\
cholecystectomy & Yes & No & Total(\%) \\
\hline Yes & 2 & 5 & $7(5.9)$ \\
No & 77 & 35 & $112(94.1)$ \\
Total & 79 & 40 & $119(100)$
\end{tabular}

CBD stones were retrieved successfully in $79(66.4 \%)$ cases. The number of patients who failed stone extraction within 20 minutes was statistically significant $(P$ 0.0001).(Table 2$)$

Table 2: The extraction time of CBD stones

\begin{tabular}{c|lll} 
& \multicolumn{4}{|l}{ Stone extraction } \\
Time of procedure & Yes & No & Total \\
\hline up to20 minute & 43 & 4 & 47 \\
> 20minutes & 36 & 36 & 72 \\
Total & 79 & 40 & 119
\end{tabular}

Failure of stone extraction was due to failure of cannulation in $10(25 \%)$, multiple impacted stones in $10(25 \%)$, and stones which were too big to be extracted in $9(22.2 \%)$ cases. In addition, 5(12.5\%) cases had CBD stricture, and the procedure was not completed because of bleeding and impaction of the dormia basket in 2(5\%) cases each. Redo ERCP was successful in seven out of nine cases. Complication occurred in $7(5.88 \%)$ patients (Table 3).

Table 3: ERCP complications among the study population

\begin{tabular}{l|ll} 
& No & $\%$ \\
\hline Bleeding & 2 & 1.68 \\
Perforation & 2 & 1.68 \\
Cholangitis & 1 & 0.84 \\
Retained dormia basket & 2 & 1.68 \\
\hline Total & 7 & 5.88
\end{tabular}

The rate of complications is $5.88 \%$ however routine serum amylase level was not done to 
know transient pancreatitis. The mortality rate was one $(0.8 \%)$ patient.

\section{Discussion}

In 1968 ERCP was introduced as a diagnostic tool and five years later endoscopic sphincterotomy transformed ERCP into an important therapeutic instrument ${ }^{6}$. ERCP, MRCP and EUS have comparable sensitivity and specificity in the diagnosis of choledocholithiasis $^{\mathbf{1 , 2}}$. However, the most adventitious role of ERCP is its therapeutic role. In Sudan ERCP is being performed in two governmental and three departments. All ERCP centers are in the capital of the country, Khartoum. Gallstone disease was reported to have variable prevalence $5-15 \%$ of the general population ${ }^{7,8}$. In contrast, in Sudan the prevalence of gallstone was reported to be $5.2 \%$. This allows us to draw a rough estimate of the number of patients with gallstone in Sudan as 2,000,000 inhabitants. The incidence of CBD stones among patients undergoing cholecystectomy was reported as $12 \%$. This allows us to estimate that there are approximately 240,000 inhabitants with CBD stones in Sudan. We feel such estimates are important for planning of establishing at least another two governmental centers for ERCP. This is because at least 180 procedures are required for a trainee to acquire a level of competence in diagnostic and therapeutic ERCP procedures ${ }^{3}$. To attain such a standard, makes the responsibility extremely hard for the existing governmental centers.

In this study, the mean age was $55.4( \pm 17.57)$ range was 19 to 90 years and the 5:1 female to male ratio are consistent with the reported data $^{11,12}$. However, the success rate of ERCP in stone extraction in this study $(66.4 \%)$ is lower than figures found in literature ${ }^{4}$. If a mechanical lithotripter was available to deal with 19 cases suffering of big and impacted stones, the success rate could have been higher. The success rate might have reached more than $80 \%$, which considered as a level of competence ${ }^{4}$ yet it would be away from optimal standard level of $90 \%$ to $95 \%$ success rate $^{4}$.

About 7(6\%) cases presented with missed stone after cholecystectomy, this could have been avoided if routine intraoperative cholangiogram is introduced as a policy. However, surgeons should be ready for re-do surgery for missed stones in our current set up.

In this study, failure of cannulation was $10(25 \%)$ which correlates well with rate of failure of cannulation in the literature ${ }^{\mathbf{1 3}}$.Also, other findings such as presence of stricture in $5(12.5 \%)$ cases, stone migration in two cases (5\%), bleeding two cases $(5 \%)$, retained retrieval basket two cases (5\%), are comparable with the reports in the literature ${ }^{\mathbf{1 4}}$. Re-do ERCP was successful in $78 \%$ i.e. seven out of nine procedures. However, this is a small number and needs further verification by wider study. Similarly, only ERCP succeeded in two out of four cases with missed stones after exploration of the CBD, again this is a small number and needs further verification by wider study. Surgeons should be ready for re-do surgery for missed stones at least in our current set up. Also, about one third of cases referred for ERCP will be referred back for open surgery with exploration of CBD.

In our current setup biliary balloon catheters were not available. Balloon dilatation is of great help particularly in cases of CBD strictures. Also, other modalities like intraductal shockwave lithotripsy are not available. Nevertheless, the complication rate was $5.88 \%$ which is similar to reports in literature ${ }^{\mathbf{1 4}}$. Patients who developed complications and those whom we failed to extract their stones $(P$ 0.0001) were referred to the surgeons in our unit where they were treated successfully.

\section{Conclusion}

ERCP, at Ibn Sina Teaching Hospital, was successful in stone extraction in 79(66.4\%) patients, failed in $40(33.6 \%)$ patients, complications occurred in seven $(5.88 \%)$ patients while death occurred in one $(0.84 \%)$ case. About one third of cases attending ERCP for stone extraction were referred back for open exploration of CBD. 


\section{References}

1- Kaltenthaler EC, Walters SJ, Chilcott J, et al. MRCP compared to diagnostic ERCP for diagnosis when biliary obstruction is suspected? BMC medical imaging2006;6:9.

2- Schmidt S, Chevallier P, Novellas S, et al. MRCP versus EUS in diagnosis of Choledocholithiasis. EurRadiol. 2007;17(1):241-50.

3-Jowell PS; Baillie J; Branch MS; et al. Prospective study of training in ERCP.Ann Intern Med 1996;125(12):983-9.

4-Huibregtse, K. Complications of endoscopic sphincterotomy and their prevention. $N$ Engl $J$ Med 1996; 335:961.

5-Rabenstein T; Schneider HT; Nicklas M; et al. Impact of skill and experience of the endoscopist on the outcome of endoscopic sphincterotomy techniques. GastrointestEndosc 1999;50(5):628-36.

6- Carr-Locke DL. Therapeutic role of ERCP in the management of suspected common bile duct stones.GastrointestEndosc 2002; 56(6): 170-4.

7- Tazuma S. Gallstone disease: Epidemiology, pathogenesis, and classification of biliary stones (common bile duct and intrahepatic). Best Pract Res ClinGastroenterol. 2006;20(6):1075-83.
8- Vincent EC. Purdon MAJ. Cholelithiasis and Cholecystitis.Manual of Family Practice.2nd Edition. 2002 Lippincott Williams \&Wilkins p313-16

9- Abdel Bagi M, Arabi M, Abdel Rahim et al. Prevalence of gallstone in Sudan: First sonographic field study in adult population. Gastroenterol. 1991;100:A307.

10- Mercer S, Singh S. Paterson I. Selective MRCP in the management of suspected common bile duct stones. HPB (Oxford).2007; 9(2): 125-130

11- Murshid KR. Symptomatic gallstones: A disease of young Saudi women. Saudi Gastroentrol. 1998; 4(3): 159-62.

12- Khuroo M,.Mahajan R, Zargar SA, et al. Prevalence of biliary tract disease in Indea: A sonographic study in adult population in Kashmir. GUT. 1989; 30(2): 201:5.

13-Udd M, Kylänpää L, Halttunen J. Management of difficult bile duct cannulation in ERCP. World $J$ GastrointestEndosc2010; 2(3): 97-103

14- Andriulli A; Loperfido S; Napolitano G; et al. Incidence rates of post-ERCP complications: a systematic survey of prospective studies. Am J Gastroenterol. 2007;102(8):1781-8. 